\title{
Concerns of Enterprises' Expansion
}

\author{
Bo Sun \\ School of Economics and Management, Jiaying College \\ 160 Meisong Road, Meizhou, Guangdong, 514015, China \\ Tel: +86-131-7870-3033Ｅ-mail: bobxox@126.com
}

Received: August 16, $2010 \quad$ Accepted: September 24, $2010 \quad$ DOI: 10.5430/ijba.v1n1p44

\begin{abstract}
To expand enterprises is a question receiving much concern. At least it needs to consider questions of scale, culture, control and strategy. From appearance, reasonable scale, harmonious culture, peace talk of control and strategy in steps make the face of enterprises' expansion; from the essence, they also constitute the base. Enterprises in owner's eyes decide their fates. 'Son Doctrine'surmounts 'Wife Doctrine', while 'Pig Doctrine' is a concept we must face and need to treat cautiously in the commercial society. This paper also proposed systematic basic model of upper growth limit through recruitment, pointing out some concerns on recruitment during enterprise's expansion.
\end{abstract}

Keywords: Expansion, Enterprises, Scale, Culture, Control, Strategy

\section{Introduction}

The economic prosperity and progress of the society are inseparable from contribution of small and medium-sized enterprises. Just because there's existence of myriad small and medium-sized enterprises, world economy and society can be dynamic and vigorous.

On later stage of last century, lots of small and medium-sized Chinese enterprises had begun giving up workshop management mode. With China's accession to WTO and constant progress of global economic integration, small and medium-sized enterprises trying to expand their markets becomes kinds of trend. Small and medium-sized enterprises doing business trans-city, trans-provincial even trans-national are emerging more and more.

From then on, how to expand and strengthen small and medium-sized enterprises has become the topic focus of up to government, university, experts \& scholars, and down to ordinary citizens as men \& women, old \& young. Analyzing and explaining 'expressway password' of small and medium-sized enterprises is undoubtedly nowadays hottest research direction. However, have we thought of: what the purpose to expand is? In other words, why do we expand enterprise?

This question seems to be ridiculous - will we 'dwindle' enterprises? Economy needs development; enterprises should be strengthened, as is undoubted. First of all, one question should be made clear. That is whether to expand or dwindle an enterprise looks no contradiction with economic development. More situations are owners and managers rack their brains to enlarge and foster their enterprises meticulously, letting their personal dreams realized gradually with enterprises' growth. However, classical strategic management theory reminds us: in some cases, reduction strategy is wise to tighten up, strip non-good assets or abandon irrelative business. Secondly, supposing no such reduction circumstances existed, we still need to consider what on earth the real purpose to expand enterprises is. Because this concerns choice of strategy, forming of corporate culture, effect of micro action, etc. Take one dreaming of getting rich for example, if he has no concrete goal to adapt, he's hardly to go prosperous for wealth. So are enterprises. Such a goal guiding enterprises' actions is necessary. Then chance to succeed will be larger. Moreover, the answer should not be simple as 'maximized profit' or 'maximized value'. Because classical financial management theory points out that an enterprise's operation goals should consider not only shareholders but also interested parts including workers, community, government, customers, etc.. Since that, one-dimensional research route can't meet realistic and ideal needs. Another point that can't be ignored is that there should be a 'limit' of enterprises' size. Enterprises 'infinitely large' only seem to be managers' flowers in mirror. Fissive development with a certain normality restricting bureaucracy overstaffed and suppressing enterprises' scale under a certain degree will benefit enterprises more (Caves, 1980, pp. 84-93). What said is this reason that 'overdone worse than undone'. Based on the above, this article believes that aspect to expand enterprises should be compound. At least it needs to consider questions of scale, culture, control and strategy.

\section{Scale}

How big to expand an enterprise? Some people advocate 'the bigger the better'. But what if the balloon blown exploded? 
There should be a critical point of scale. As for how to select it, even possibility of whether could be selected, all need further discussion.

Some enterprises blindly pursues speed and expansion through multiplication, laying very long frontier in their unfamiliar domain, playing 'positional warfare', as lead to limited fund dispersed in large-spanned market and 'being defeated respectively', stuck in finance, fell in trap hopeless to survive (Singer, 1995, pp. 269-276). A speech is extremely classical: success experience always twists because of enlargement. Losing lesson is relatively more real. Business owners who experienced it are sure to say 'yes'.

Everyone yearns for rich family and big enterprise, so do gamblers. Gamblers are taking their own lives and fates to risk. They should be responsible for their behaviors - zero or negative property is not out of expectation. But if a manager bets with enterprise's future and fate, he is joking with the enterprise's destiny, irresponsible! Giant Building (planned 70 stories) coveted the 'highest in China' but halted only at the third storey. There's no alternative but to say Shi Yuzhu had despised normal development rule of enterprise. The original intention to expand enterprise is kind, but we mustn't be eager for quick success and immediate gain, not to mention breaking through objective limit and pursuing 'indefinite large' blindly.

\section{Culture}

On small and medium-sized enterprises' embryonic stage, established all alone by its leader, it betrays the founder's thought style and behavioral criterion everywhere in management. Its cultural origin has great relations with the entrepreneur's undertaking concept, management philosophy, managerial style and courage quality. No doubt it has advantages, but still it has fatal drawbacks. The following two 'eye diseases' are becoming current epidemic disease of small and medium-sized enterprises.

\subsection{Managers'red eyes}

Enterprises are not merely the entrepreneur's but also belong to staffs and societies. Enterprises to strengthen should have the faith - staff-based, popularized and socialized, that's the must to enterprises' longevity. The small and medium entrepreneurs need to realize intellectual capital's value in the future information age, to treat talents as equal capital owners indeed and seek correspondence of fund and intellectual capital, to construct enterprise management concept and development vision together instead of waiting for the other party's bid and then treating him as a tool. Meanwhile, talents as outstanding ones in professional society, seeking win-win development with enterprises and sharing fair allocation system of wealth creation is their pursuit. It's necessary for entrepreneurs to change their mode of thinking, liberating talents out from simple personnel notion, to endow them rights and obligations of equal sharing enterprises' profit. Only so, talents could be really incorporated into enterprises, enterprises could have harmonious value concept with talents, then producing so-called common 'vision' and melt into corporate culture consciously. Small and medium-sized enterprises mustn't ignore communication, understanding and harmonious relation between entrepreneurs and talents. Talent's absolute approval of entrepreneurs and enterprise's prospect should be strived for. If corporate culture itself fetters managers' collective spirit which advocates stepping forward together, such enterprises are quite dangerous. Some conceited managers envy talents, which is seriously contradicted with thought of 'capable only'. Their enterprises tend to be complacent and conservative, as hard to make further progress (Bai, 2004). This paper holds that 'substitutive promotion' is a good countermeasure. That is only when one executive finds his substitute who is competent and no worse than him in certain time (such as eight years), may he himself get further promotion. Doing so redounds to adjusting managers' \& enterprises' interests reach unanimity and constructing cultural atmosphere of solidarity \& 'lessening personal feud' in organization.

\subsection{Enterprises' myopia}

Another situation is enterprises' short-sightedness in business. When business's not big, customers are treated as God for market occupying. Once succeeds - the enterprise grows bigger, it will probably bully guests for its great. Some 'just-expanded' enterprises are more possible to meet and suffer enterprises' myopia, thus absorbing large enterprises' shortcoming — producing bureaucracy similar togovernment system, or difficult coordination between departments. Small business grows up in competition depending on their fine products and service. What the pity is, some enterprises' products and service can no longer win their superiority after their success. This thought favoring 'quick money' is hard to ensure enterprises' ever-green. Many small and medium-sized enterprises wait for their occasions only to fish for once, or keep changing their addresses, or satisfied just to get by with no ambition. Such enterprises want to occupy niche market at first for their products' quality or characteristics. Once succeeds, profit target dominates, and quality gets relaxed intentionally or unintentionally.

Myopia in life can't be fatal, but myopia in business might lead enterprises into impasse dilemma (Liang, 2005, pp. 20). 
Ephemerality of small and medium-sized enterprises is common in nearly all countries. How many sad stories of short-lived enterprises the passed focus 'Qinchi' and 'Chinese Viagra' narrates! And how many textbook-styled faults were left to descendants! Enterprises hoping great development have to take long-term sight. They have to pay price for growing, but some tuition is too costly to afford. Current situation is not the only, broad \& long term view should be taken. Harmonious culture will lead to harmonious market, only so can enterprises develop harmoniously and healthily.

\section{Control}

In the above 'culture' we talked about managers influencing corporate culture by protective measures for personal interests. If the actor is the owner instead of managers, it evolves to a battle of enterprise's control power. Vying between shareholders is unfavorable to company, as only restricts company's up-going, thus makes it impossible to expand though desiring so. Had people gone through starting an undertaking, they all have such feeling that it's discordance between partners that causes enterprises' collapse. This inconsistence could be coordinated if simple and shallow. But if there's essential difference (either large or small, the difference often exists objectively) among management thoughts, operative plans etc. between investors, battle of control power over the enterprise is to start. Unexpected but frequently happened result is: one part leaves in a huff with his investment, as makes the enterprise even smaller.

China revised its 'Codes of Corporation' again in 2005, and one person individual proprietorship Co., Ltd. got approval. Comparatively, it's a break-through to 'Personal Individual Proprietorship Law', and which suffer the most are just 'Personal Individual Proprietorship Law' and 'Partnership Law'. The previous personal sole proprietorship now can become company and take limited responsibility while still keeping control over the enterprise. As to previous partnership, each part may set up a one person individual proprietorship Co., Ltd. of his own without relying on the other. But for these two situations, what owners mainly value is the very control power over company. And that's the must threshold of enterprises' expansion. 'To share skin with tiger' is the nightmare of many small enterprise owners, but the vigorous activities for outside investment inviting \& seducing of every country have fully confirmed the principle - 'to profit, offer first'. Caring but oneself can't expand enterprises, generosity \& compatibility is the best choice to get rich. Company itself shouldn't be victim of corporate politics!

\section{Strategy}

Corporate strategy is an integrated plan of enterprises' growth, goals and countermeasures based on sufficient studying enterprises' law of survival and development. Offensive, defensive or withdraw strategy determines enterprise's different paces and ploys respectively. Simple 'attack-and-hit' can't last, 'to apprehend, better leave him at large first' will always produce miraculous effect of 'one step retreat, two steps gains'. Consequence of adhering rigidly to financial report profit, ignoring response of market and raising speed blindly is always 'more haste, less speed'. Enterprises' deflation or expansion should be connected with strategy closely. Withdrew fist hits more strongly, so do enterprises.

To some extent, the hodiernal small and medium-sized enterprises understand market better. Their market behaviors have incomparable advantages when either enter or withdraw. Another point couldn't be ignored is, the investment of small and medium-sized enterprises still concentrates on 'visible' projects that can produce benefit quicker, and there's not too much excessive investment pursuing technological leading, so they can adjust or even contract their lines while meeting 'cold snap' to avoid more loss.

In general, contraction is not small and medium-sized enterprises' final purpose. Though situation severe, the winter might not be too long or too cold for them. They can cultivate intensively on traditional market while positively conserving energy \& power to welcome development climax of new round. Expansion can be expected after undergoing these hardships.

\section{Enterprises in owners' eyes}

There's a question we haven't touched yet which is what owners regard enterprises as? Here we explain it combining some western views.

In American, demarcation between company and individual is definite, each residing its own. But situation of small and medium-sized enterprises in some other countries might not be like this. Some entrepreneurs grow enterprises as their wives, allowing no participation from anyone. Some entrepreneurs grow enterprises as their sons, caring too much when little, supervising seriously when young $\&$ restless, controlling less when mature (to establish subsidiaries). Some people grow company as pigs only to sell - raise one and sell one, raise a flock and sell a flock. The majority treat enterprises as wives, minority treat enterprises as sons. The third ones are quite few, but still exist. Fact needs practitioners and thinkers of each country to seek their own path of corporate governance. 


\subsection{Wife Doctrine}

Chinese emphasize sobriety while American are overflowing with enthusiasm. But both Chinese and American men regard wife as their private only and care meticulously. This notion taken into enterprise, the owner will devote himself to all the enterprise's constructions heart and soul, sparing no effort, as deserves other managers even large enterprises' executives learning. But even if the owner were made by steel, how many nails could be produced by him? As noted previously, 'Wife Doctrine' pays attention to control power the most. This decides the enterprise couldn't really enter and compete in market, not to mention its grand expansion blueprint.

\subsection{Son Doctrine}

'Son Doctrine' is a progress to 'Wife Doctrine' for it further helps enterprises to act according to market law. Especially during enterprises' mature periods, owners have got the mind to fight sufficiently \& freely, so the enterprise may expand. And the close monitoring during starting and growing stages can also be deemed as serious responsibility taking. Remember not to let go the target too early when doing so, since the technology of occasion choosing is not simple. Rising and ebbing of Giant Group can explain the reason well.

\subsection{Pig Doctrine}

'Pig Doctrine' is the most commercial of the three, also the most revolutionary in market, striking people's traditional thought fiercely, and has earned stirring effect. Investors penetrating capital market search for objectives like 'talent scouts'. Once a target is chosen, they will try their all to take it over, strip non-good, pack and then resell it. Because 'Pig Doctrine' is extremely utilitarian, its shortcoming is neglection of target enterprises' own strategy orientation - focus of attention is but enterprises' shells, no matter buying or selling, thus encourages enterprises' repeating and variability. Years ago there's a famous Dalian 'Shide Department' in Chinese Soccer League, whose boss - XU-Ming, bought and sold several Chinese top, class-A and -B teams utilizing abundant talent resources of Soccer City - Dalian, gaining a lot. But he got extensive attack \& resisting from fans in Sichuan and other places, even his home - Dalian. People tasted sharpness of 'Pig Doctrine' when surprising and amazing.

\section{Upper growth limit through recruitment}

There's an upper limit of enterprise's growth through recruitment (Figure 1) which is decided by a circuit that can reproduce endogenously. Activities of recruitment could produce accelerated growth or expansion for a certain period, and then growth starts to slow down (usually not realized by person inside system), finally stops growing. Moreover, it may even possibly starts to deteriorate post.

The accelerated growth period is engendered by one (or several) 'reinforcing circuit'. The following 'gradual growth period' is brought by 'adjustment circuit' when growth reaches certain degree and suffers some 'limitation'. Such limitation could possibly be of HR capable limitation itself, or a response to growth by either interior or exterior. Its 'accelerated deterioration period' (if occurs) originates from reverse operation of 'reinforcing circuit' which causes deterioration speed up and the original result increasingly withers.

At first we may consider, 'Why do we worry about the problem not yet happens? The enterprise is expanding vigorously at a growth pace of high speed.' Later we would meditate, 'Truly is there the problem. But what we need to do is just to layout a better disposition of the staff.' And after some otherdays passing by we might discover, 'the more diligently we recruit personnel, the more seemingly we're stepping in-situ.' These are just the early alarm signals of upper growth limit through recruitment (Peter \& Guo, 2001, pp. 61-67).

Management countermeasures to upper growth limit through recruitment should be: Do not impel 'reinforcing (growth) circuit', but to remove (or weaken) sources of limitations.

Enterprise example: an enterprise starts to employ well conditioned applicants of minority to please government's relative policy. The chosen ones are arranged in company's different work groups. A resolute program of action is then worked out simultaneously to strengthen support to this kindhearted plan. At first everyone's support to this plan unceasingly grows, but afterwards other staffs' resistance finally emerges. They don't think these tyros are well qualified. Therefore when work groups receiving more pressure to accept new member, their resistance tends to be more intense.

Innovation revelation: recruitment is not catholicon; its efficacy's complete display should resort to other management measures. Operation of enterprise's innovation team might be evident at first, thereupon everyone gets infatuated with yesterday happiness and over-trust previous work method - resulting innovation become conservation or falling into a circulation. Matrix type is better for innovation team, and project group should reorganize periodically.

Other examples: 
Take employee's orientation training as an example. His skill and confidence get gradually enhanced at early stage, progressing quickly. But later on he starts to suffer restriction of his gift or capacity, only to master new kills could help break through growth limitation. But he feels embarrassed and uncomfortable when starting learning new skills.

A newly created enterprise rapidly expands. But when it reaches a certain scale, its growth gradually slows down. What it needs now is managerial techniques more professional and organization more perfect.

A work team of new product's operation is extremely well, thus attracting many newcomers. But the team's performance is far less than the past. This is because differences of work attitude and value concept between new and old members.

A technological innovation is initially introduced. Then it incurs opposers' increasing resistance which leads to failure of its propagation.

One leader of two factions intriguing against each other receives enterprise's penalty or is transferred. The other faction would rapidly reproduce and expand. The result is not a unified one, instead other interior differences makes it fission again (Sun, 2007, pp. 4452-4455).

\section{Conclusions}

Enterprises' expansion is a progressive course, impossible to accomplish in one action. From appearance, reasonable scale, harmonious culture, peace talk of control and strategy in steps make the face of enterprises' expansion; from the essence, they also constitute the base. 'Son Doctrine' surmounts 'Wife Doctrine', while 'Pig Doctrine' is a concept we must face and need to treat cautiously in the commercial society. There's upper growth limit through recruitment to enterprises. Real farsighted enterprises should focus on institutional improvement, to expand steadily, even sacrifice some immediate interest for long-term run. These enterprises are the ones most successful who laugh in the end. The very hope of world economy is just them.

\section{References}

Bai, SL. (2004). Study of corporate culture re-engineering during private business' growth. Tianjin: International Business School of Nankai University (in Chinese).

Caves, RE. (1980). Industrial organization, corporate strategy and structure. Journal of Economic Literature, 58, 84-93

Liang, X.M. (2005). To cure myopia of private business. Talents, 7, 20 (in Chinese)

Peter, S., and Guo, J.L. (2001). The Fifth Discipline: the Art \& Practice of the Learning Organization. Shanghai: Shanghai Sanlian Bookstore, pp. 61-67 (in Chinese).

Singer, B. (1995). Contours of development. Journal of Business Venturing, 10, 269-276

Sun, B. (2007). Recruitment's support to innovation. In Institute of Electrical and Electronics Engineers Computer Society, (Eds.), 2007 International Conference on Wireless Communications, Networking and Mobile Computing. Shanghai: IEEE Communication Society. pp. 4452-4455

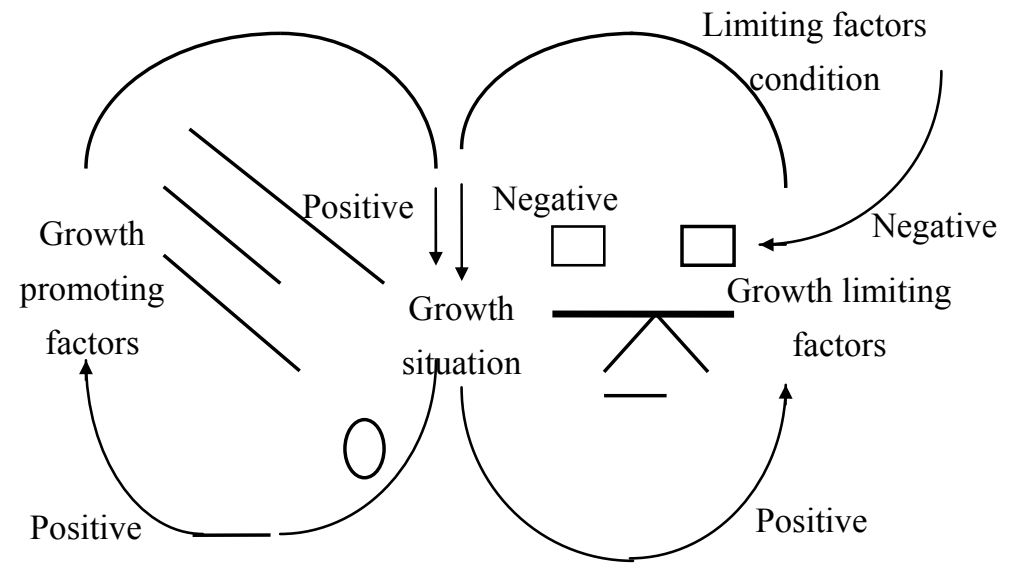

Figure 1. Systematic basic model of upper growth limit through recruitment 